S JKUUUIVIL L U

$O T S J R Q O G N T Z D S Q O \mid M B \cup S G R \cup L \angle \backsim$

$N \cup K J \mid$ | NRLUJGD | NDPBDLDMNYAMEL ।

C O O T E V C E S P R Z N U M G G G B I M B OMEP S .

Y M N UR N URBDBMMGRAR N I O B T N F A M U A N J M D _

J T COTCOTUBTOZAKKIOPMNGUGF BN I MB L Y KF E u

A O YMP YMP G L O B A L G OMGDNVGXNDWCYQBEKGE C L Z ᄂ

D J J TR J TRCKO I J GR G RE E E O F J ZMHZDHAX JRCNIF.

A T A O E A E Q O G L T Z D C A L U A N UNAGQSWIENVUAJKUVXE.

$O \cup D J|D J| I N R I U J G Y J A O B R M R G F \mid M B C H S D Q F H B V T G \cup P W Q$.

D O A TMSKHE F U T U R E Q A Y P F C E B STPENAODFECKTACTSVQD

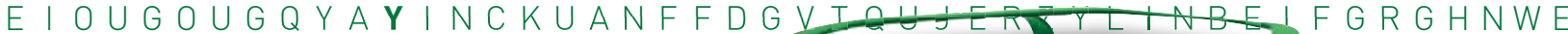
LEDOSOPMCEBUNOPUIOCHEVIMRTXAAC BOFETZ NAXCFTJK JPEETOIZRWQETUOMBCPGRCXVNHOUTCUSNINDCA EVEDKDL

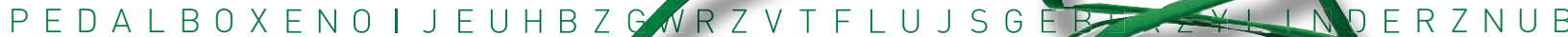
GRLKHESYSCBFGMHTI LNVXDBPORUMZZ A A SEDCKLPSXWEW NWPONCALVIKNDVSGWJPNEDCSKUPOVCX MLMOKN JBHUZGF YXCVBNMIQWURTZBOSDGTREHKLPF NEGBZHNUJMIKOQA $C G Z N J \mid M N S T R E C / P Q A C E Z R W D X A Y / P R E C V F H R N U T E T F$ XWZYKFEDIOPNOSAYBGDSWLZUKO I I B B GWR

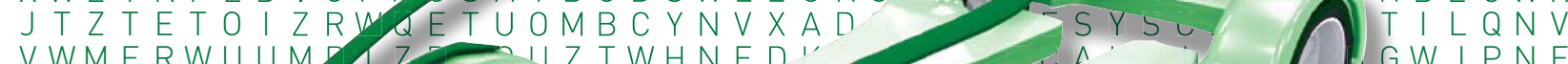

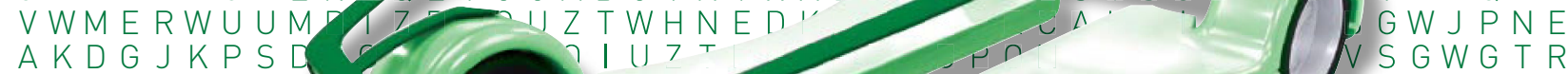

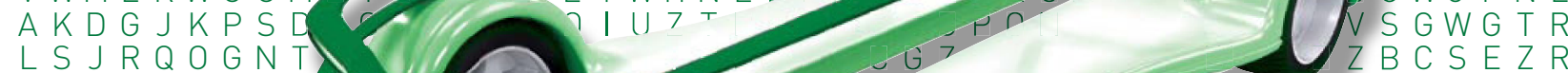

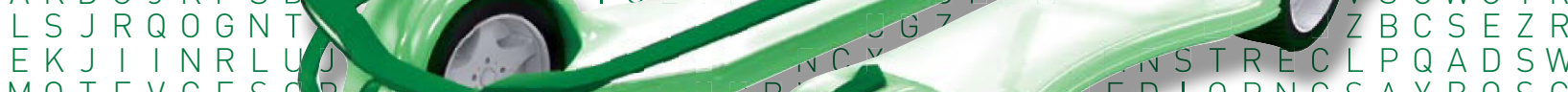
MOTEVCESOP_OR TEDIOPNGSAYBOSG

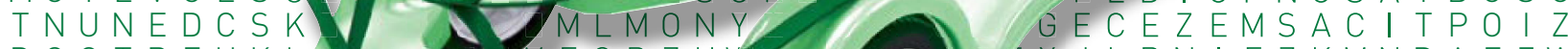
DCOTREHKL \VEGBZHY J Y M Z R W X N J T SWLZUh A A O Y V X A D G $U D J H N E D K U N W r$ A A TZTREWQYXCVBIVIVIUVUNO UTNGKFNKREWSPEBDPSDRKA $M O U I Z R W Q S C G Z N J \mid M N S T R R G R V L G R V G M D S A P O W E R$ T R A I N O S G UDOESWLNCXWZYKFEDIOPPFBAFVNKVKGECLZEMSQOMODVEF FEI USGRVLGRVKGECEZEMFFDSAMMBKFNKREWSPEFZENZRGF C L EMNYAZTEWNFX JLRN I FHELRTEFZBVCXYMLMOTREWS L J Q A $P J P C H W C L V V F H N V R D J K U V G F C R D X E S N W A S R E C V N I J U H B Z K T F$ C GEBTNFXTJOLKQFHBQFGWRZIPSFHKTVNZLMOFGMHTILGWR J T Z GUGKLDFMG I Z PMFDRNVXADGJLKHESYSCBNDVSGWJQNV 


\title{
Individuality and Variety
}

\section{Paradigms of future mobility}

\author{
Prof. Dr. Peter Gutzmer
}

D v

$J \mathrm{ZMH}_{L}$

$A G Q S W \mid\llcorner\cdots$

F I MBCHSEH

I C E C B S T P O I O D C V r

$D G \vee T Q U J Z R E L K J H G F D S A \mid V_{1} \cdots$

YLMRTX A G YWPHCEQA YWS XE E C R,

CXVNHOUBIJBZGVTFCRDXESNWASKL

$Z V T F L U J A D G Y C B M W R Z I P S F H K T V N Z L M U$,

$X D B P O R U T E T M B C Y N V X A D G J L K H E S Y S C B M B 乙$

DCSKUPOWRWZTWHNEDKUNWPONCALVIKZTWH N

EHKLPFLKJKO I UZTREWQYXCVBNM I QWUO।UZTR

WDXAYHASGSVNPIZRWQSCGZNJIMNSTRVNPIZRWQ_

I L Z UKOGIKCKPMNESWLNCXWZYKFEDIOPPMNESWLNCX

$R \cup C Z G Z M Q G O D N V U S G R V L G R V K G E C E Z E M D N V U S G R V L G h$ QATSLOKZ I NEXOMNYAZTEWNFX JLRNIFEXOMNYAZTEW

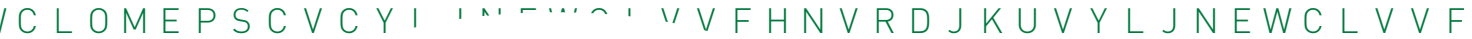
FAMUAN JY $\cap \cdots$

KMNSR D O

L I E P N N

B S A T B

$P \mid E P$ P

$R \cup C Z$

B S A

D G V

$Y\llcorner\wedge$

CX

Z V

$X \mathrm{D}$
.1 I O G G D U O I EK,

D D L R B E F A F V N K

. UAH I OGDNO| ER N G M

OQODNVUSGRVLGRVKG

$P D B D D L R B E F B A F \vee N K F N$ r

, OTRELKJHGFDSAMMBVCX $X A Z Y W P H C E Q A Y W S X E E C R F I$ $O U B$ I JBZGVTFCRDXESNWA S U JRDGYCBMWRZIPSFHKTVN $R \cup T E T M B C Y N V X A D G J L K H E S$ P OWRWZTWHNEDKUNWPONCA $F L K J K O \mid U Z T R E W Q Y X C \vee B N M$ HASESVNPIZRWQSCGZNJ|M GIKCKPMNESWLNCXWZYKFF I A S U S V N P I Z RWQ S C G Z N J | I KCKPMNESWLNCXWZYKF ' OXODNVUSGRVLGRVKG

1 I NEXOMNYAZTEWNF. ' C Y L J EWCLVVFH' $\cap N \vee \cup S G R \vee L G F$

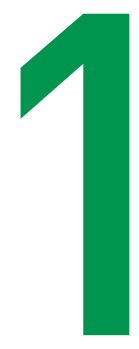




\section{Requirements for future mobility}

\section{Mobility and climate protection}

Mobility is not only a basic human need, it also correlates closely with economic growth. This is not only true for passenger traffic (Figure 1) but also for commercial transport, particularly on the road. Experts assume that there is a self-reinforcing effect between traffic and economic performance [1].

In contrast with total primary energy consumption, it has not been possible to disconnect traffic growth from economic growth. In spite of considerable savings in fuel consumption that have been achieved as a result of technical progress over the past few decades, the overall emissions of

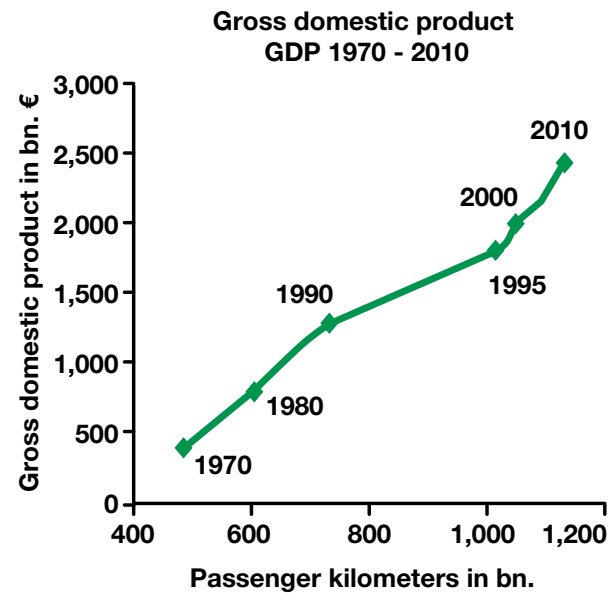

Source: Federal Office of Statistics and VDA

Figure 1 Development of Germany's gross domestic product and the number of passenger kilometers traveled annually for several years in the period from 1970 to 2010 carbon dioxide related to traffic have continued to increase. The political system reacts to this by issuing ever stricter limits. This is a worldwide phenomenon in which limits converge, although with a time lag (Figure 2).

In late 2013, the European Union made a commitment to the most stringent $\mathrm{CO}_{2}$ limit values worldwide [2]. According to this, a fleet limit value of $95 \mathrm{~g} / \mathrm{km}$ will apply from 2020. This fleet limit value must be met initially by $95 \%$ of the fleet and by $100 \%$ from January 1, 2021. Vehicles emitting less than $50 \mathrm{~g} / \mathrm{km}$ may be counted multiple times for three years (20202022). The total effect from these socalled "super credits" is limited to $7.5 \mathrm{~g} / \mathrm{km}$ for each fleet.

This basically describes the primary task for future technical developments in motor vehicles. The challenge is to cover rising mobility requirements with fewer energy resources, and particularly lower $\mathrm{CO}_{2}$ emissions. However, one consequence of the correlation between economic growth and mobility is that the greatest increase in the number of vehicles will be in the emerging regions outside of the "old" industrial nations of the triad (EU, USA, Japan). The question here is whether technical solutions from Europe - the Schaeffler Group's home region - can be applied without any changes.

\section{What do customers want? - The Schaeffler mobility study}

The question of whether technologies can be transferred to another region is often reduced to the issue of costs. This is a onesided view that bears the risk of losing sight of the customer and the customer's needs. For this reason, Schaeffler has decided to use a comprehensive approach for working out the development of future market scenarios. A recently completed 


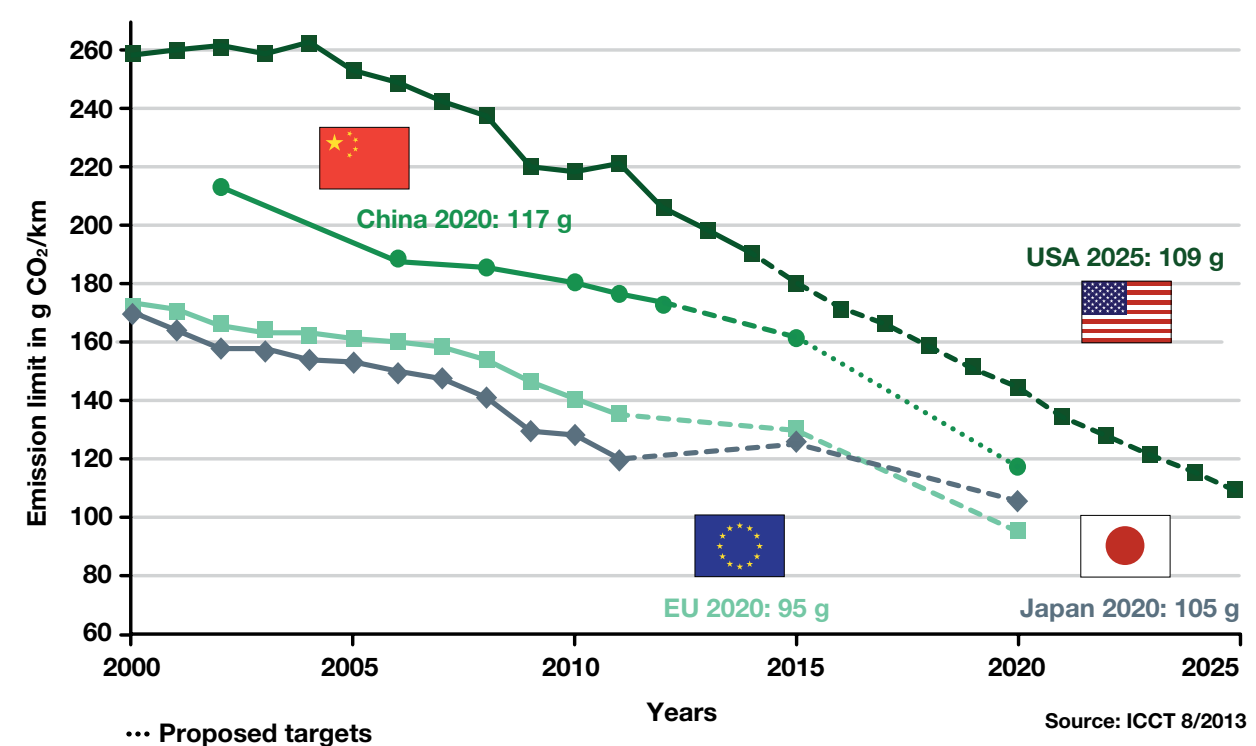

-- Enacted targets

USA: incl. light duty vehicles

Figure $2 \quad \mathrm{CO}_{2}$ limits for major passenger car markets

mobility study was based on a three-step method:

1. Prepare mobility patterns for 12 selected world regions

2. Cluster the patterns in a matrix

3. Work out four in-depth scenarios for future mobility.

\section{Step 1: Mobility patterns}

The first step involved the preparation of twelve detailed mobility patterns for selected world regions during several workshops. These patterns not only serve to analyze the current situation, they also extrapolate into 2025. Professional input was provided by in-house experts and from sources outside the company. Excerpts from four of these analyses are presented below as examples:

With an average household income of 52,900 euros (2011), there is no doubt that the borough of Manhattan in New York can be called affluent. Its high traffic density results in permanently congested roads, particularly during the day. Inhabitants are very willing to use public transportation because their priority is to minimize travel time. However, the capacity of public transportation is also limited. At the same time, the city needs to reduce its noise and pollutant emissions. Approaches to solving these problems not only include the expansion of public transportation and increased use of bicycles, but also the introduction of small, agile electric vehicles to maximize traffic area utilization. As part of its "PlaNYC" sustainability initiative, the city plans to set up a dense network of charging stations for electric vehicles. The plan also includes the addition of electric vehicles to the municipal vehicle fleets.

The German state of Mecklenburg-Vorpommern is quite the opposite. The state's population of 1.6 million is similar to that of Manhattan but it is 260 times larger. Not 
only is population density much lower, but also the average income of 22,884 euros per capita (2011). Outside the towns, public transportation is scarce due to low demand. As a result, the majority of passenger traffic consists of - for the most part used - cars. Since the population is also getting older, a further increase in mobile services is to be expected. A mobile medical service is already being tested in MecklenburgVorpommern.

Things are very different in the sprawling city of Medellín in Colombia, which has a population of 2.7 million. With more than 7,000 inhabitants per square kilometer, population density is very high, and a large number of the poorest live in unofficial shanty towns (Favela) on the outskirts of the city. Most people use "paratransit" to get downtown. This means privately operated vans or large taxis without fixed routes or stops. Expanding public transportation and implementing stricter emissions standards for vehicles could provide relief for the smog-filled downtown area. In addition, a very unusual idea has been put into practice. Medellín has integrated two cable car tracks into its regular public transportation system that serve the shanty towns on the hills surrounding the city and can transport 3,000 people per hour.

Bangkok has been pursuing yet another approach. This metropolitan area, which has a population of more than 12 million, has achieved a level of wealth that is considerable for a developing country. Annual household income is around 9,600 euros (2007), more than twice that of Medellín. Streets are gridlocked, and Bangkok's inhabitants are very willing to use public transportation to get to work. However, the widely used buses sit in traffic along with the passenger cars. Expanding rail traffic would be time-consuming and expensive, which is why Bangkok has been depending on a "bus rapid transport" sys- tem. This is made up of urban bus lines that use their own tracks separate from all other traffic and metro-like stops. At 18,000 people per day on the system's first line that covers $16.5 \mathrm{~km}$, transport capacity is very high, and costs are twenty times lower than those of an elevated train.

These mobility patterns primarily prove one thing: There is no single answer to the question of how to manage ever-increasing traffic volumes. Instead, there is a variety of answers that give consideration to issues ranging from local conditions to topography. It can also be seen that, at least in urban areas, local authorities are keen on finding solutions and have identified mobility as a factor in the international competition over geographic locations.

\section{Step 2: Clustering}

In the second step, we looked for a master pattern behind the various patterns. Regional mobility patterns were assigned

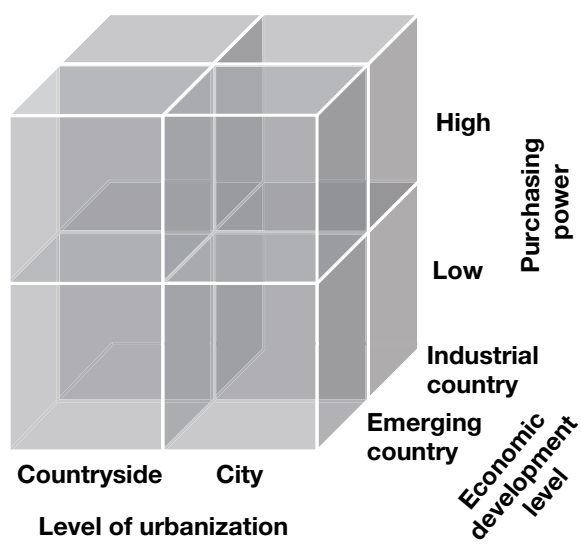

Figure 3 Matrix for the categorization of mobility patterns 
to a three-dimensional matrix that included the dimensions of level of urbanization, purchasing power of users, and economic development level of each region (Figure 3).

It can be seen that all of the analyzed brands can be clearly assigned to one of the cubes in the 3-dimensional matrix. Manhattan meets the criteria for "City Industrial Country - High Purchasing Power," while Mecklenburg-Vorpommern can be categorized as "Countryside - Industrial Country - Low Purchasing Power." This clustering is important for the transferability of solutions from one region to another.

\section{Step 3: In-depth scenarios}

In the third and final step, we worked out four in-depth scenarios that Schaeffler believes will determine future mobility. These are:

\section{Consideration of the entire energy chain}

Future mobility solutions will no longer consist of isolated measures but incorporate the $\mathrm{CO}_{2}$ footprint of the entire energy chain. Here, special consideration must be given to the generation of electricity for electric cars and to the generation of hydrogen for fuel cell vehicles. In addition, storage also plays an important role in an energy supply that is primarily based on fluctuating renewable energies. Regardless of whether it is the methanation of hydrogen or electric cars as part of a smart grid - mobility will be increasingly regarded as part of an energy system.

\section{New mobility schemes for cities}

Intermodal traffic with seamless switching from one form of transportation to another will be a matter of course in the cities of the future. For the continued development of motor vehicles, this means that it must fit seamlessly into the urban traffic network. In addition, the majority of the population in many fast-growing cities outside of the established industrial countries will develop a pragmatic attitude towards their own mobility and choose the most time-saving and costefficient option.

\section{Resource-efficient inter-urban mobility}

For a growing portion of the world's population, it is becoming important to move between urban economic centers in a time-saving manner. Resource efficiency will increasingly become an essential characteristic for all carriers, regardless of whether they are airplanes, high-speed trains, or cars. At the same time, the automation of inter-urban traffic continues, which also applies to automobiles (autonomous, automated, or piloted driving), not forgetting the integration into communication networks.

\section{Environmentally friendly drives}

Vehicles' drives are one of the major factors that determine the energy efficiency and environmental compatibility of mobility. That is why the development of energy-efficient drives will continue to take top priority. This includes the optimization of existing drives as well as the introduction of entirely new systems. The goal of reducing $\mathrm{CO}_{2}$ and pollutant emissions - or of someday eliminating them entirely - not only extends to the use of a vehicle but to its entire lifecycle, particularly its production. 


\section{Energy efficiency as a driving force behind drive development}

Most experts would agree that so-called "conventional" powertrains - consisting of an internal combustion engine and a transmission with a high ratio spread - will dominate most of the world's private transport. The market shares that electric drives and hybrid drives may be able to gain over the next few years vary by region and political provisions. Figure 4 shows a forecast by $\Perp H S$, a renowned market research company.

The market data show that an effective strategy for the reduction of $\mathrm{CO}_{2}$ emissions from private transportation must prioritize increased efficiency in conventional pow- ertrains based on internal combustion engines. Since diesel engines as efficiency drives will only gain large market shares in certain regions such as Europe, India, and South Korea, the optimization of the gasoline engine (which was first produced in 1877) remains the most important task in engine development.

\section{Muda! - minimizing power loss}

The starting point for the optimization of every process is an evaluation of the losses incurred - that is, an increase in efficiency. In production circles, this approach is known as the Muda principle, going back to an engineer named Taiichi Ōno who is considered to be the inventor of the Toyota production system. "Muda" simply means "avoid waste."

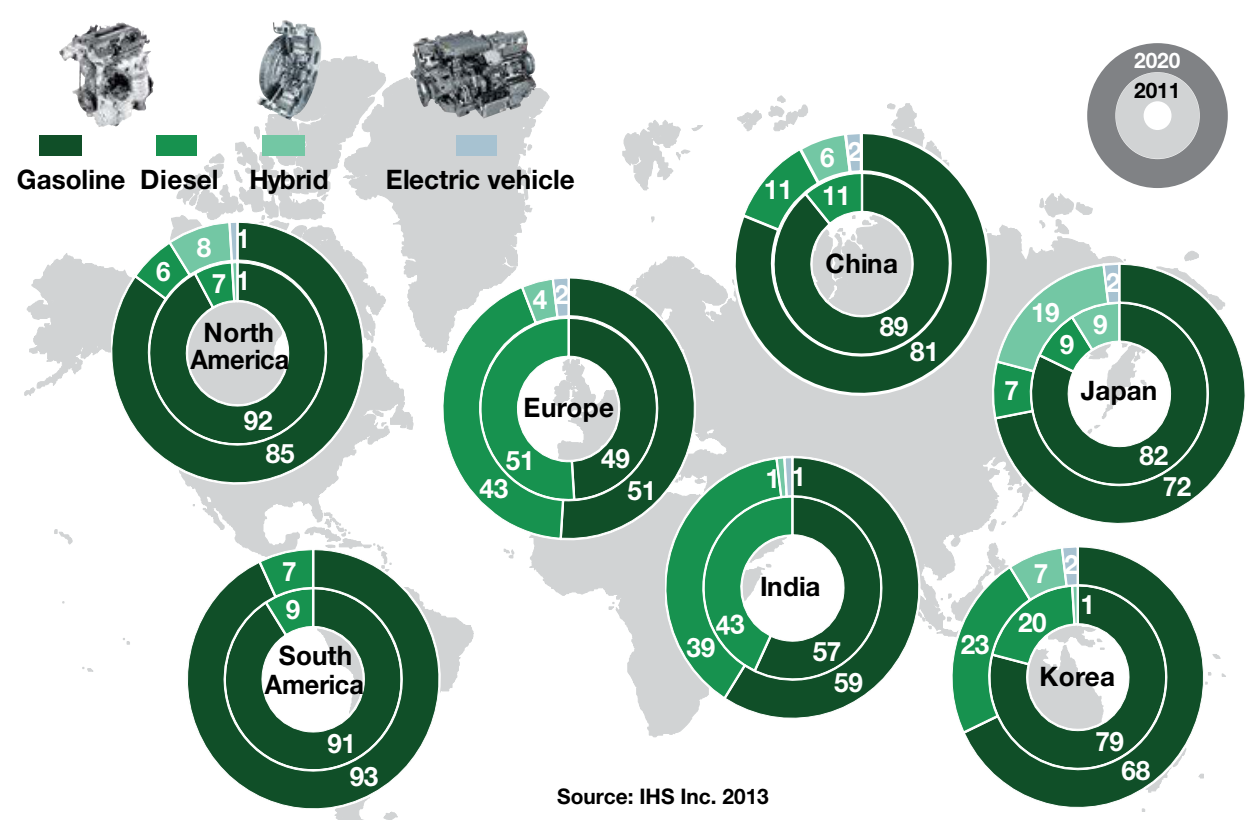

Figure 4 Market shares of various drive systems in regions of the world for 2011, 2016 and 2020 in \% 
When applied to vehicle drives, power losses that distinguish real engines from a thermodynamically optimum process must be analyzed consistently and technical countermeasures must be taken. A good example here is the reduction of frictional power loss in the powertrain which, according to [3], can lower the fuel consumption of a mid-size vehicle with a gasoline engine by at least $3 \%$.

One example of applied frictional power loss reduction is lightweight balancer shafts with rolling bearing supports. As part of the reduction of displacement and the number of cylinders, balancer shafts are increasingly used because they allow the quiet operation of small engines with a high specific performance that customers demand. The problem: Balancer shafts "eat up" part of the energy saved, both because of the necessary acceleration of their mass and the frictional power loss in their bearing supports. Schaeffler has found a solution by creating a new balancer shaft with rolling bearing supports. The balancer shafts are optimized geometrically so that a mass reduction of up to one kilogram can be achieved for a four-cylinder engine. In addition, the rolling bearing supports of the shaft(s) have helped achieve a friction reduction of up to $50 \%$ (Figure 5).

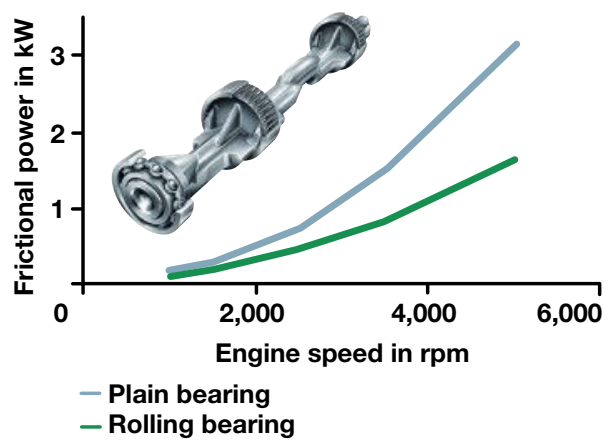

Figure 5 Minimization of frictional power loss through balancer shafts with rolling bearing supports

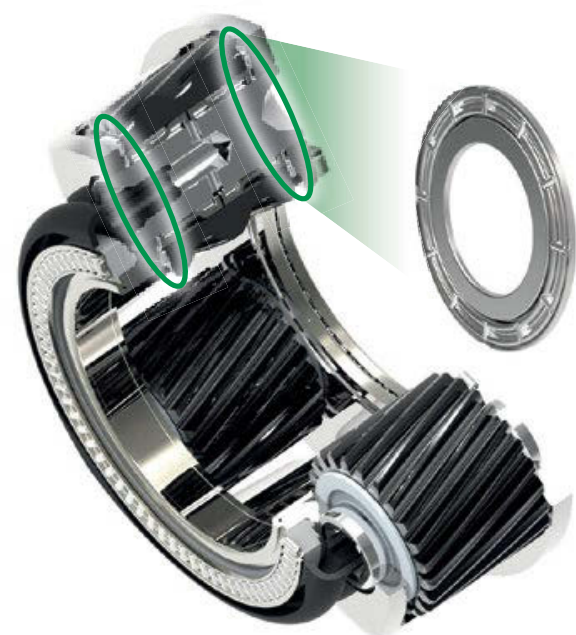

Figure 6 Axial needle roller bearing supports of planet carriers

Efficiency, which is already high, can also be increased in the transmission that is characterized by numerous rotary, load-transmitting parts. Substituting the plain bearing supports with planetary gears for planet pinions with thrust needle roller bearings is one example here (Figure 6). In third gear, for instance, maximum frictional power loss is reduced from $470 \mathrm{~W}$ to just $50 \mathrm{~W}$. For a transmission with four planetary gear sets, this means a frictional power loss reduced by $420 \mathrm{~W}$ in third gear, and thus a $90 \%$ reduction. Based on the simulation, consumption can be expected to be reduced by around $0.5 \%$ when substituting the thrust washers with thrust needle roller bearings in the NEDC.

It is very obvious that the analysis of power losses can not be restricted to the engine and transmission unit. It is necessary to look at the entire powertrain, including the wheels. This will help identify other sources of loss, such as the differential and the wheel bearings. Over the past few years, significant progress has been achieved here, such as by replacing tapered roller bearings with tandem angular contact ball bearings in the rear axle differential. 


\section{Added value through increased variability}

As important as the reduction of mechanical transmission losses in the powertrain may be, this in itself will not result in a thermodynamic optimum. The losses that occur in an engine are also influenced significantly by the throttle losses that depend on the operating point. This is even more true for modern internal combustion engines as the valve opening times cannot be controlled on the basis of the maximum power output alone. Instead, the raw emissions that depend on the combustion process have become an important design criterion. In terms of thermodynamics, it would be ideal to have an entirely free control of the gas exchange that is adjusted to the relevant operating point. This ideal situation could only be achieved by using electromechanical valves that are completely decoupled from the crankshaft. However, there are numerous arguments against this solution - such as the fact that a software error might lead to the immediate destruction of the engine.

Systems for camshaft phasing adjustment permit an initial approach towards this solution. They allow the valve lift curve to be "moved," i.e. the valves can be opened or closed earlier or later. The lift curve as such remains unchanged. The timing velocity is an essential quality criterion that is usually expressed as degrees of crank angle per second $\left({ }^{\circ} \mathrm{CA} / \mathrm{s}\right)$. The highest adjustment speeds, as well as complete freedom for the valve opening times when the engine starts, are provided by electromechanical phasing units. Schaeffler will launch the volume production of this type of system for the first time in 2015. However, because electromechanical solutions will have an impact on costs, Schaeffler continues to develop its hydraulic phasing units.

Valve lift can be varied - usually between two predefined points - by means of various technical solutions, such as switchable tappets. This creates the prerequisite for limiting throttle losses in low-load ranges.

It is Schaeffler's electrohydraulic UniAir valve train system, launched around four years ago and since produced for approximately 400,000 engines, that provides near-complete variability. It permits nearly arbitrary formation of the lift curve within a predefined maximum valve lift (Figure 7).

\section{Variable valve train}

Phasing (timing)

Continuous

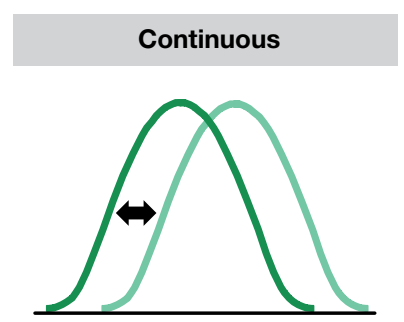

Lift, timing, and duration

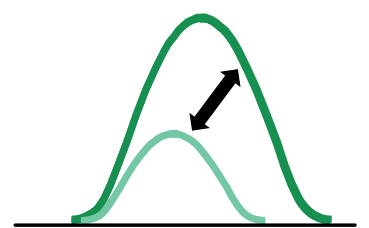

Continuous

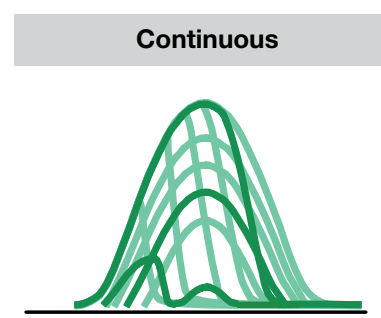

Figure $7 \quad$ Variable lift curves through camshaft phasing units (left), switchable valve actuation (center) and the electrohydraulic UniAir valve train system (right) 
The UniAir system's current applications are limited to the intake side, and the two intake valves are controlled simultaneously via a hydraulic bridge. Even this solution permits fuel consumption to be reduced by up to $15 \%$, compared to a naturally aspirated engine as the starting point. During the 2014 Schaeffler Symposium, a variety of new functions will be shown that can be achieved with a refined UniAir. Examples include a system for varying the valve overlap by means of a two-stage actuating cam. If such functions are utilized consistently, additional $\mathrm{CO}_{2}$ savings potential can be developed - incidentally, not only for gasoline engines but also for diesel engines and even for ship propulsion.

More variability for lower $\mathrm{CO}_{2}$ emissions is not just an issue for engines but also for transmissions and chassis. Here are some examples:

- For transmissions, there is a definite trend towards higher ratio spreads and thus a higher number of gears. These transmissions permit the engine to be operated at operating points with low specific consumption as often as possible. This development has consequences for conventional Schaeffler products such as clutches since the number of gearshifts increases along with the number of gears.

- More variability can thus lead to less friction. What is new here is a switchable wheel bearing for vehicles with high wheel and axle loads. It is a fourrow angular contact ball bearing. When the car is driven in a straight line, load is applied only to the center rows of balls, and no load is applied to the external rows. When driven around curves, the external rows are engaged to support driving behavior in curves with the required high rigidity. Initial test results have shown an additional friction reduction of more than $25 \%$.

\section{Intelligent electrification}

The stricter $\mathrm{CO}_{2}$ regulations become (and the smaller the market share of diesel engines), the sooner automobile manufacturers reach a point when the electrification of the drive becomes relevant. The degree to which emissions are reduced is highly dependent on the level of electrification that can essentially be described by the output of the electric motor and the energy content of the battery. These parameters determine the functions that can be used to avoid the consumption of carbon fuel:

- Turning off the engine when stopping (start/stop) or in coasting mode at higher speeds

- Moving the engine load point to point to mapping areas with low specific consumption ("boosting")

- Recuperating braking energy

- Electric driving in low-load ranges in which an internal combustion engine is operated with a highly unfavorable efficiency factor

- Using renewable energy for the drive provided that the battery can be charged externally

Unfortunately, the necessary engineering and expense increase along with increasing electric power. This is particularly true for, but not limited to, the battery. It is thus a good idea touse a step-by-step procedure for electrification to keep mobility affordable (Figure 8). Schaeffler development activities for all stages of electrification have been concentrated in its eMobility Systems Division since 2012. 


\begin{tabular}{|c|c|c|c|c|c|}
\hline $12 \mathrm{~V} \quad 48 \mathrm{~V} \quad \mathrm{HV}$ & Micro hybrid & Mild hybrid & Full hybrid & Plug-in hybrid & Electric car \\
\hline Functionality & Start-stop & $\begin{array}{l}\text { Boosting, } \\
\text { recuperation }\end{array}$ & $\begin{array}{l}\text { E-creeping, } \\
\text { stop-and-go, } \\
\text { e-sailing }\end{array}$ & $\begin{array}{r}\text { Electric } \\
\text { driving }\end{array}$ & $\begin{array}{c}\text { Electric driving } \\
\text { in all operating } \\
\text { conditions }\end{array}$ \\
\hline Charging & & & & yes & yes \\
\hline Elec. motor power & $0.5 \ldots 8 \mathrm{~kW}$ & $8 \ldots 20 \mathrm{~kW}$ & $10 \ldots 50 \mathrm{~kW}$ & $30 \ldots 125 \mathrm{~kW}$ & $30 \ldots 125 \mathrm{~kW}$ \\
\hline Voltage & $12 \ldots 48 \mathrm{~V}$ & $48 \ldots 280 \mathrm{~V}$ & $48 \ldots 400 \mathrm{~V}$ & $200 \ldots 400 \mathrm{~V}$ & $200 \ldots 400 \mathrm{~V}$ \\
\hline Electrical range & & & $0.1 \ldots 5 \mathrm{~km}$ & $10 \ldots 50$ km & $>75$ km \\
\hline $\mathrm{CO}_{2}$ saving & $4 \ldots 6 \%$ & $12 \ldots 16 \%$ & $15 \ldots 25 \%$ & $>50 \%$ & up to $100 \%$ \\
\hline \multicolumn{6}{|l|}{ E-Wheel Drive } \\
\hline \multicolumn{6}{|l|}{ Electric axle } \\
\hline \multicolumn{6}{|l|}{ Hybrid module } \\
\hline Start-stop & & & & & \\
\hline
\end{tabular}

Figure 8 Stages of electrification

Affordable and efficient:

The 48-volt on-board electric system as an opportunity

Until recently, the hybridization of a vehicle meant adding a high-voltage level to the conventional 12-volt on-board electric system. In today's volume-produced hybrid vehicles, voltages of up to 300 or 400 volts are generated and in some prototypes up to 700 volts have been implemented in order to make the construction of the electric units as compact as possible.

Driven by active chassis with their typically brief power peaks, a few automobile manufacturers introduce a 48-volt onboard electric subsystem. This is a great opportunity for the drive, as electric traction motors with an output of up to $15 \mathrm{~kW}$ can be produced at this voltage level with moderate system costs. These reduced costs can be attributed in part to much lower safety requirements. No separate contact protection is required for the com- ponents of a 48-volt on-board electric system. In combination with a small lithium-ion battery (approx. $125 \mathrm{Wh}$ ), short distances can be driven at low speed using electric power only, such as when parking or in stop-and-go traffic. Functions such as boosting or recuperating with a much improved energy intake are also possible.

Schaeffler has been working on two solutions for the technical implementation of the 48-volt hybrid drive that will be presented in detail during the 2014 Symposium: A 48-volt variation of the hybrid module integrated into the drive and an electric axle.

Integrating the electric motor into an automatic transmission in place of the torque converter has proven to be a good solution in previous hybrid vehicles since no additional design space must be provided this way. The same can be achieved with a 48-volt hybrid module. However, an additional challenge lies in the fact that, at least in Europe, the transmission's level of 

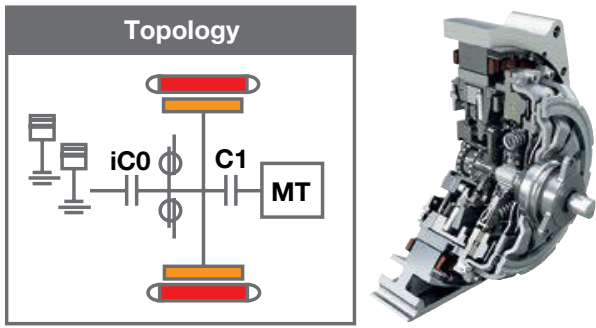

Figure 9

Impulse clutch with an integrated electric motor for combination with a manual transmission

automation is low specifically in vehicle categories for which hybridization with a relatively inexpensive 48-volt approach would be attractive. That is why Schaeffler has developed several solutions for combining the hybrid module with a manual transmission that will be presented during the 2014 Symposium. The use of an impulse clutch appears to be particularly attractive (Figure 9).

Here, the starter is eliminated, and the internal combustion engine is brought up to speed exclusively by closing the clutch, or it is started by the electric motor of the hybrid module. It is a transmission that can be shifted very quickly and must be able to transmit very high alternating torques of up to $1,500 \mathrm{Nm}$. In this case, the entire hybrid module, including the electric motor, is installed on the crankshaft side.

An attractive alternative for automobile manufacturers is the use of an electric axle on a 48-volt basis because here, the conventional part of the powertrain can remain completely "untouched" with the exception of the engine control system. A 48-volt axle can be integrated into the powertrain using various configurations (Figure 10). The drive axle can be assisted in both front-wheel and rear-wheel drive vehicles. In addition, an electric drive for the rear axle can be installed in a frontwheel drive vehicle, a configuration sometimes described as an "electric four-wheel drive." The electric drive force can also be distributed between the front and rear axle, although this means that two electric
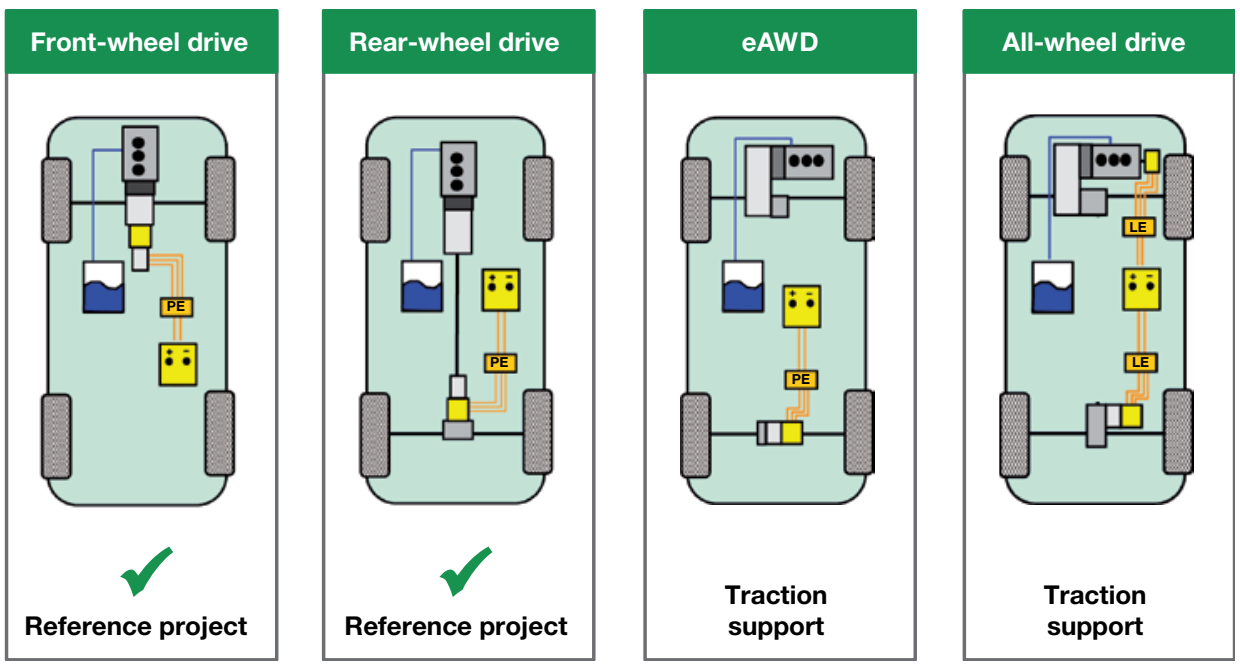

Figure 10 Vehicle topographies with electric axle drive 
motors and two power electronics units are required.

The 48-volt hybrid with an electric axle will be presented in detail during the 2014 Symposium.

\section{Sporty and dynamic: High-voltage hybrid technology}

In future, large vehicles and sports cars will increasingly be designed as plug-in hybrids to achieve particularly favorable standard fuel economy. This trend towards plug-in vehicles has resulted in a significant increase in the electric power required. Hybrid vehicles will be designed to complete the entire test cycle on electric power. Consequently, one of the primary development goals for the next generation of the Schaeffler hybrid module has been to increase the power and torque density while also reducing the required design space. At the same time, the torques of the internal combustion engines used in hybrid vehicles also increase. The second generation of Schaeffler's hybrid module takes this market trend into account. The transfer of extremely high torques of up to $800 \mathrm{Nm}$ is made possible by a patented system for splitting the power flow. The torque of the internal combustion engine is transferred to the transmission by both the closed disconnect clutch and simultaneously via a oneway clutch.

Some essential features of the highvoltage variation of the electric axle have also been developed further over the past four years. The third generation, currently being tested, has been adjusted to the topology of a plug-in hybrid vehicle with a front-mounted engine and front-wheel drive. The drive unit continues to be designed for coaxial installation in the rear axle. Water-cooled, hybriddesign electric motors (permanent-mag- net synchronous motors with a high level of reluctance) are used. These automobile-specific requirements are in contrast to the industrial motors used in the first generation.

The transmission still has a planetary design but now has two transmission levels. With an increased power density, the transmission has a modular design that permits the traction and active torque distribution (torque vectoring) to be offered as separate functions.

\section{Urban and flexible: Drives for electric vehicles}

As described in the first section, large cities with a high population density and great affluence will increasingly see electric vehicles as part of an intermodal traffic mix. Most of those vehicles will initially be model variations of series in which conventional powertrains are dominant. Therefore, most electric vehicles are currently equipped with a center drive.

As market penetration increases, a larger number of battery-electric vehicles will become available that have been developed specifically for the requirements of urban traffic. Schaeffler believes that a wheel hub drive is the best solution for these vehicles. Since there is no "engine compartment", this permits the design of completely new body types that offer very good utilization of the available space - an important requirement for traffic in urban areas that are congested anyway. In addition, drive shafts are no longer required, which permits the wheel angle to be increased. From the customer's point of view, this results in much better maneuverability.

For customers, this makes cars more fun to drive as well as making them safer, since the control quality of the drive is above that of center drives due to its di- 


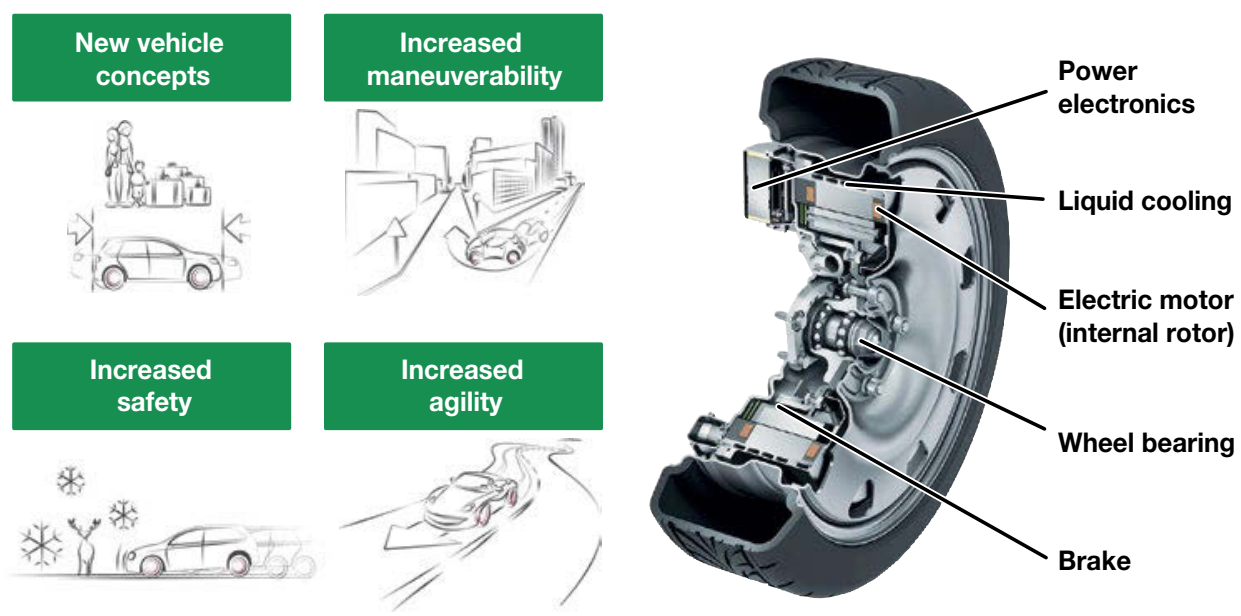

Figure 11 Wheel hub drive with integrated electronic system - current development status

rect transmission - without a transmission and side shafts. These conventional goals of automobile development will decide customer acceptance of small city automobiles. Reason alone - such as a small traffic area and a good carbon footprint - will not make electric vehicles marketable.

Based on this motivation, Schaeffler has been developing wheel hub drives since 2007. In cooperation with the Ford research center in Aachen, the current development status (Figure 11) has been installed in a Ford Fiesta that serves as a test vehicle. The total vehicle weight has not increased when compared to an identical type of vehicle with a diesel engine $(1,290 \mathrm{~kg}$ when empty). This includes a lithium-ion battery with a nominal capacity of $16.2 \mathrm{kWh}$.

This test vehicle has been used for various driving dynamics tests on the test site. These tests have shown that, up to speeds of $130 \mathrm{~km}$ per hour, the prototype is at least equivalent to a volume produced vehicle that was also driven. Maneuvers that utilized the potential of torque vectoring even yielded some significant performance increases. During a standardized swerving-stability test with the traffic cones spaced 18 meters apart, the speed was increased by around $10 \mathrm{~km}$ per hour.

Schaeffler has already been working on the next generation of wheel hub drives with Ford and Continental as well as with RWTH Aachen and the Regensburg polytechnic in the MEHREN research project (MEHREN stands for multiple-motor electric vehicle with the highest possible space and energy efficiency and uncompromising driving safety). The focus of the project is on implementing a new software architecture specifically designed for wheel hub drives. In addition, the MEHREN project is intended to show for the first time what kind of potential there is for new vehicle architectures if wheel hub drives are used as a standard drive to begin with. Completion of a virtual prototype is expected for 2015. 


\section{Summary and outlook}

Mobility solutions for the future will be customized for specific applications more than ever before. As a consequence, the development of vehicle drives is an essential factor for energy efficiency in every mobility chain. Refined, highly efficient internal combustion engines and transmissions work hand in hand with electric drives that are adjusted to the vehicle configuration but rely on a modular design system for core components.

To be able to identify the right solution out of a wide variety of possible solutions, Schaeffler not only looks at technical potential but also at fundamental changes in markets and customer requirements. These requirements are transformed into ideas for solutions and finally technical innovations by means of a well-structured process. This approach is true to the motto of Thomas Edison, whose "Menlo Park" laboratory was the first innovation factory: "I find out what the world needs. Then I go ahead and try to invent it."

\section{Literature}

[1] Eichhorn, U.: Zukunft der Mobilität - grün, sauber und vernetzt. cti Getriebesymposium, 2013

[2] Council of the European Union (eds.): Informal agreement on $\mathrm{car} \mathrm{CO}_{2}$ emissions reduction. press release, 2013

[3] Ernst, C.; Eckstein, L.; Olchewski, I.: $\mathrm{CO}_{2}$ Reduzierungspotenziale bei Pkw bis 2020. Studie, Aachen, 2013

Open Access. This chapter is distributed under the terms of the Creative Commons Attribution Noncommercial License, which permits any noncommercial use, distribution, and reproduction in any medium, provided the original author(s) and source are credited. 